\title{
Nicotine promotes chronic obstructive pulmonary disease via inducing pyroptosis activation in bronchial epithelial cells
}

\author{
RUBING MO ${ }^{1 *}$, JUN ZHANG $^{2 *}$, YONGXING $\mathrm{CHEN}^{1}$ and YIPENG DING ${ }^{3}$ \\ Departments of ${ }^{1}$ Pulmonary and Critical Care Medicine, ${ }^{2}$ Emergency and ${ }^{3}$ General Practice, Hainan General Hospital, \\ Hainan Affiliated Hospital of Hainan Medical University, Haikou, Hainan 570311, P.R. China
}

Received June 30, 2021; Accepted November 24, 2021

DOI: $10.3892 / \mathrm{mmr} .2022 .12608$

\begin{abstract}
Nicotine is one of the primary components in cigarettes, which is responsible for addiction. Numerous studies have investigated the effects of nicotine on pulmonary disease. The health of epithelial cells is important in the development of chronic obstructive pulmonary disease (COPD). Accumulating evidence has suggested that epithelial cell death may initiate or contribute to the progression of a number of lung diseases via airway remodeling. Pyroptosis is a unique form of inflammatory cell death mediated by the activation of caspase- 1 and the NOD-like receptor protein-3 (NLRP3) inflammasome. The present study aimed to evaluate whether pyroptosis of epithelial cells was involved in the progression of COPD. The normal human bronchial epithelial cell line 16HBE was treated with 0.1 or $1 \mu \mathrm{M}$ nicotine. Then the proliferation ability of 16HBE cells was detected by CCK-8. Cell death was detected by flow cytometry analysis and TUNEL assay. Subsequently, the levels of pro-caspase 1, caspase 1, IL-1 $\beta$, IL-18, NLRP3, ASC and cleaved GSDMD were examined by western blotting. It was revealed that nicotine treatment significantly induced cell death and suppressed proliferation of 16HBE cells. Furthermore, nicotine exposure increased the expression levels of caspase-1, IL-1 $\beta$, IL-18, NLRP3, apoptosis-associated speck-like protein and gasdermin D in 16HBE cells. Therefore, the present study concluded that nicotine treatment induced
\end{abstract}

Correspondence to: Dr Yipeng Ding, Department of General Practice, Hainan General Hospital, Hainan Affiliated Hospital of Hainan Medical University, 19 Xiuhua Road, Haikou, Hainan 570311, P.R. China

E-mail: ypding@263.net

Dr Yongxing Chen, Department of Pulmonary and Critical Care Medicine, Hainan General Hospital, Hainan Affiliated Hospital of Hainan Medical University, 19 Xiuhua Road, Haikou, Hainan 570311, P.R. China

E-mail: chenyongxing1969@163.com

${ }^{*}$ Contributed equally

Key words: chronic obstructive pulmonary disease, epithelial cells, pyroptosis, caspase-1, NOD-like receptor protein-3 pyroptosis in $16 \mathrm{HBE}$ cells, which may be associated with the progression of COPD.

\section{Introduction}

Chronic obstructive pulmonary disease (COPD) is responsible for $>1,400,000$ annual mortalities worldwide, and is characterized by persistent airflow limitation and limited therapeutic options (1). There are currently 64 million patients with COPD and 3 million cases of COPD-associated mortality every year estimated by the WHO. COPD is predicted to be the third leading cause of mortality in the world by 2030 (2). Annually, COPD treatment costs $\leq € 141.4$ billion in Europe and $\sim 50$ billion in America $(3,4)$. Emphysema is the major pathological diagnostic factor associated with COPD, which affects the distal space of the terminal bronchioles, and is associated with an irregular inflammatory response and oxidative imbalance of the lungs to toxic particles or gases $(1,5)$. COPD mainly manifests by incomplete reversible airflow limitation, which significantly decreases the quality of life and exercise endurance of patients (6). Therefore, it is important to determine the underlying mechanism and identify effective preventative measures of COPD to further improve the survival rate of patients with COPD.

Overwhelming evidence has suggested that cigarette smoking is the leading cause of COPD worldwide (5). Between 80 and $90 \%$ of patients with COPD are smokers, and 10-15\% of smokers will develop COPD (5). It has been shown that there are $>4,500$ chemical compounds in the gas mixture generated by cigarette smoking, most of which are toxic, and 72 compounds are carcinogenic substances $(7,8)$. Nicotine, the principal addictive component in cigarette smoking, is considered to be the main factor driving the pathogenesis and progression of pulmonary disease $(9,10)$. Substantial evidence has supported the promoting effect of nicotine on COPD on a long-term basis (11) and smoking cessation is the top priority in the treatment of COPD (12); however, the underlying mechanisms remain largely unknown.

Inflammation and cell death are the two critical pathological mechanisms of COPD $(13,14)$. Enhanced cell death can be observed during the destruction of lung tissue in both humans and mice $(14,15)$. Previously, cell death was typically ascribed to apoptosis and necrosis; however, several other forms of cell death have been identified recently, such as pyroptosis (16). 
Pyroptosis is a unique form of inflammatory cell death, which is mediated by the activation of caspase- 1 and the NOD-like receptor protein-3 (NLRP3) inflammasome (17). The NLRP3 inflammasome is a multiprotein intracellular innate immune sensor mainly composed of NLRP3, apoptosis-associated speck-like protein (ASC) and pro-caspase-1 (18). Caspase-1 activation is responsible for the maturation of pro-IL-18 and pro-IL-1 $\beta$ (19), whereas NLRP3 activation induces the cleavage of gasdermin D (GSDMD), which rapidly creates cell membrane rupture and leads to intracellular protein release, resulting in an inflammatory reaction (20). Non-infectious and infectious stimuli can both trigger pyroptosis (21). It has been reported that cigarette smoke can induce the expression of caspase- 1 and its downstream target molecules, IL-1 $\beta$ and IL-18, in the bronchoalveolar lavage, serum and sputum of patients with COPD $(22,23)$. Furthermore, inflammasome activators have been shown to be increased in the airway of patients with COPD, including extracellular ATP, ROS and damage-associated molecular patterns (24). These previous findings indicate a critical role for pyroptosis in COPD progression.

Bronchial epithelial cells are the first anatomical barrier exposed to noxious gases and particles of cigarette smoke, which can initiate airway remodeling in COPD (25). Apoptosis of epithelial cells serves a crucial role in the pathogenesis of COPD via airway remodeling $(26,27)$. Numerous factors associated with COPD, including cigarette smoke, have the potential to cause apoptosis of epithelial cells $(28,29)$. Nevertheless, to the best of our knowledge, it remains to be fully elucidated as to whether pyroptosis is involved in epithelial cell death upon nicotine exposure.

The present study aimed to investigate whether epithelial cells undergo pyroptosis in COPD progression. These findings may improve understanding of the underlying mechanisms of COPD and provide valuable information for the diagnosis and treatment of COPD.

\section{Materials and methods}

Cell culture. The normal human bronchial epithelial cell line $16 \mathrm{HBE}$ is a common cell line used to study COPD pathogenesis in vitro (30). $16 \mathrm{HBE}$ cells (American Type Culture Collection) were cultured in RPMI-1640 medium (Gibco; Thermo Fisher Scientific, Inc.) supplemented with $10 \%$ fetal bovine serum (Gibco; Thermo Fisher Scientific, Inc.). The cells were grown in $75-\mathrm{cm}^{2}$ flasks at $37^{\circ} \mathrm{C}$ in a humidified atmosphere containing $5 \% \mathrm{CO}_{2}$ and were passaged $1: 3$ using $0.25 \%$ trypsin when they reached $80-90 \%$ confluence. Nicotine was purchased from Nacalai Tesque, Inc. $16 \mathrm{HBE}$ cells were treated with 0.1 or $1 \mu \mathrm{M}$ nicotine for $48 \mathrm{~h}$ at $37^{\circ} \mathrm{C}$, as previously described (31).

Cell proliferation assay. The proliferation of 16HBE cells was evaluated using the Cell Counting Kit-8 (CCK-8) assay (Dojindo Laboratories, Inc.). 16HBE cells were seeded in 96-well plates $\left(1.0 \times 10^{4}\right.$ cells/well), and were exposed to $0,0.1$ or $1 \mu \mathrm{M}$ nicotine for $0,48,72$ and $96 \mathrm{~h}$ at $37^{\circ} \mathrm{C}$ (31). Finally, $10 \mu \mathrm{l}$ CCK-8 solution was added to $100 \mu \mathrm{l}$ RPMI-1640 medium in each well for $2 \mathrm{~h}$. Absorbance values were measured at a wavelength of $450 \mathrm{~nm}$ using an automated microplate reader (Molecular Devices, LLC).
Flow cytometry. The death of $16 \mathrm{HBE}$ cells $\left(1 \times 10^{6} / 100 \mu \mathrm{l}\right)$ was analyzed using an Annexin V-FITC and PI staining kit (cat. no. A211-01/02; Vazyme Biotech Co., Ltd.) according to the manufacturer's instructions. Flow cytometry was performed on a FACSCalibur flow cytometer (BD Biosciences) and the rate of cell death (\% of $\mathrm{PI}^{+}$cells) was analyzed with FlowJo software (FlowJo, LLC, version 10.6.0).

Reverse transcription-quantitative PCR ( $q P C R)$. Total RNA was isolated from each group of $16 \mathrm{HBE}$ cells using TRIzol ${ }^{\circledR}$ (Thermo Fisher Scientific, Inc.; cat. no. 15596026). The concentration of RNA was determined using an ND-2000 Spectrophotometer (Thermo Fisher Scientific, Inc.). RNA was reverse transcribed into cDNA by M-MLV Reverse Transcriptase kit (Elk Wuhan Biotechnology Co., Ltd. cat. no. EQ002) with the following temperature protocol: $42^{\circ} \mathrm{C}$ for $50 \mathrm{~min}$ for the reverse transcription reaction; $99^{\circ} \mathrm{C}$ for $5 \mathrm{~min}$ to inactivate the reverse transcriptase; and $4^{\circ} \mathrm{C}$ to store the reverse transcription product. qPCR was performed with the KAPA SYBR FAST qPCR Kit (Kapa Biosystems; Roche Diagnostics) using a 7300 Real-Time PCR System (Applied Biosystems; Thermo Fisher Scientific, Inc.). Data were normalized to the housekeeping gene GAPDH. The mRNA levels were measured using the $2^{-\Delta \Delta \mathrm{Cq}}$ method of quantification (32). All qPCR experiments were replicated at least three independent times. The thermocycling conditions used for qPCR were: Initial denaturation at $95^{\circ} \mathrm{C}$ for $10 \mathrm{~min}$; followed by 40 cycles of $95^{\circ} \mathrm{C}$ for $15 \mathrm{sec}$ and $60^{\circ} \mathrm{C}$ for $1 \mathrm{~min}$. The following primer sequences were used: GAPDH, forward 5'-TGACTTCAACAGCGACACCCA-3', reverse 5'-CACCCT GTTGCTGTAGCCAAA-3'; pro-caspase-1, forward 5'-ACA AGACCTCTGACAGCACG-3', reverse 5'-TTCACTTCCTGC CCACAGAC-3'; IL-18, forward 5'-GCTGAAGATGATGAA AACCTGGA-3', reverse 5'-GAGGCCGATTTCCTTGGT CA-3'; and IL-1 $\beta$, forward 5'-CCAGCTACGAATCTCCGA CC-3', reverse 5'-TATCCTGTCCCTGGAGGTGG-3'.

Western blotting. Proteins were extracted from treated $16 \mathrm{HBE}$ cells by RIPA lysis buffer (Beyotime Institute of Biotechnology; cat. no. P0013B) and were quantified using the BCA method. Proteins (30 $\mu \mathrm{g}$ per lane) were separated by SDS-polyacrylamide gel electrophoresis on $10 \%$ gels and were electrophoretically transferred to polyvinylidene fluoride membranes, which were blocked with $5 \%$ skimmed milk for $1 \mathrm{~h}$ at room temperature. The following primary antibodies were used overnight at $4^{\circ} \mathrm{C}$ : Rabbit anti-pro-caspase-1 (1:1,000 dilution, cat. no. ab179515; Abcam), rabbit anti-caspase-1 (1:500 dilution, cat. no. 22915-1-AP; Proteintech Group Inc.), rabbit anti-IL-1 $\beta$ (1:500 dilution, cat. no. A1112; ABclonal Biotech Co., Ltd.), rabbit anti-IL-18 (1:500 dilution, cat. no. A1115; ABclonal Biotech Co., Ltd.), rabbit anti-NLRP3 (1:1,000 dilution, cat. no. ab263899; Abcam), rabbit anti-ASC (1:1,000 dilution, cat. no. ab283684; Abcam), rabbit anti-cleaved N-terminal GSDMD (1:1,000 dilution, cat. no. ab215203; Abcam) and mouse anti-GAPDH (1:500 dilution, cat. no. 60004-1-lg; Proteintech Group, Inc.). Horseradish peroxidase-conjugated goat anti-rabbit/mouse IgG (1:5,000 dilution, cat. no. BA1054/BA1051; Boster Biological Technology) was used as a secondary antibody for $1 \mathrm{~h}$ at room temperature. Immunoreactive protein bands 
were detected by ECL hypersensitive chemiluminescence kit (cat. no. P0018M; Beyotime Institute of Biotechnology) with an Odyssey Scanning System (version 3.0, LI-COR Biosciences).

Immunofluorescence analysis. Immunofluorescence staining of $16 \mathrm{HBE}$ cells was performed as previously described (33). $16 \mathrm{HBE}$ cells $\left(5 \times 10^{5}\right)$ plated onto cover glasses were fixed with $4 \%(\mathrm{w} / \mathrm{v})$ paraformaldehyde for $15 \mathrm{~min}$ at room temperature. Rabbit anti-caspase-1 (1:50 dilution; cat. no. 22915-1-AP, Proteintech Group Inc.) was added to the fixed 16HBE cells and incubated at $4^{\circ} \mathrm{C}$ overnight, followed by incubation with Goat anti-Rabbit IgG F(ab')2 secondary antibodies (dilution, 1:1,000; cat. no. 31234; Invitrogen) for $2 \mathrm{~h}$ at room temperature. 4',6-diamidino-2-phenylindole (DAPI, dilution, 1:1,000; cat. no. 62248; Thermo Fisher Scientific, Inc.) was used to stain nuclei at room temperature for $10 \mathrm{~min}$. The images were acquired using a FV3000 confocal fluorescence microscope (Olympus Corporation).

TUNEL assay. $16 \mathrm{HBE}$ cells $\left(4 \times 10^{4}\right.$ cells $\left./ \mathrm{cm}^{2}\right)$ were seeded onto cover glasses. After $24 \mathrm{~h}$, the cells were treated with 0.1 or $1 \mu \mathrm{M}$ nicotine for another $48 \mathrm{~h}$ followed by fixing with $4 \%(\mathrm{w} / \mathrm{v})$ paraformaldehyde for $15 \mathrm{~min}$ at room temperature. Then the cells were subjected to a TUNEL assay (DeadEnd Fluorometric TUNEL System; Promega Corporation) according to the manufacturer's instructions. Briefly, cells were incubated with $250 \mu \mathrm{l}$ of TUNEL labeling solution in one well of a 24-well plate for $1 \mathrm{~h}$ at $37^{\circ} \mathrm{C}$ covered with aluminum foil. Then cells were incubated with PBS containing DAPI nucleic acid stain (dilution, 1:1,000; $1 \mathrm{mg} / \mathrm{ml}$ solution, cat. no. 62248; Thermo Fisher Scientific, Inc.) for $10 \mathrm{~min}$ at room temperature to stain nuclei. TUNEL positive (TUNEL+) cells were calculated by counting the number of stained cells in five separate field per slides using a Leica confocal microscope TCS SP2 (Leica Microsystems GmbH).

Statistical analysis. All experiments were repeated at least three times in vitro and all data were analyzed using GraphPad Prism 7 (GraphPad Software, Inc.). Data are presented as the mean \pm SD. Differences were analyzed for significance by one-way ANOVA followed by Duncan's post hoc test. $\mathrm{P}<0.05$ was used to indicate a statistically significant difference.

\section{Results}

Nicotine exposure triggers $16 \mathrm{HBE}$ cell death. The present study used nicotine-treated $16 \mathrm{HBE}$ cells as an in vitro model of COPD. To explore the potential role of the primary component of cigarette smoke, nicotine, in the progression of COPD, nicotine was used to treat $16 \mathrm{HBE}$ cells. In $16 \mathrm{HBE}$ cells incubated with 0.1 or $1 \mu \mathrm{M}$ nicotine, the proliferation rate significantly decreased compared with the control group (Fig. 1). Conversely, the cell death rate was significantly increased by nicotine (Fig. 2). In order to further characterize nicotine-induced $16 \mathrm{HBE}$ cell death, the cells were stained with TUNEL. The results revealed that the number of TUNEL-positive cells was markedly increased in nicotine-treated groups compared with the control group (Fig. 3).

Epithelial cells display characteristic features of pyroptosis after nicotine exposure. To elucidate the relationship between nicotine and pyroptosis, 16HBE cells were used for in vitro

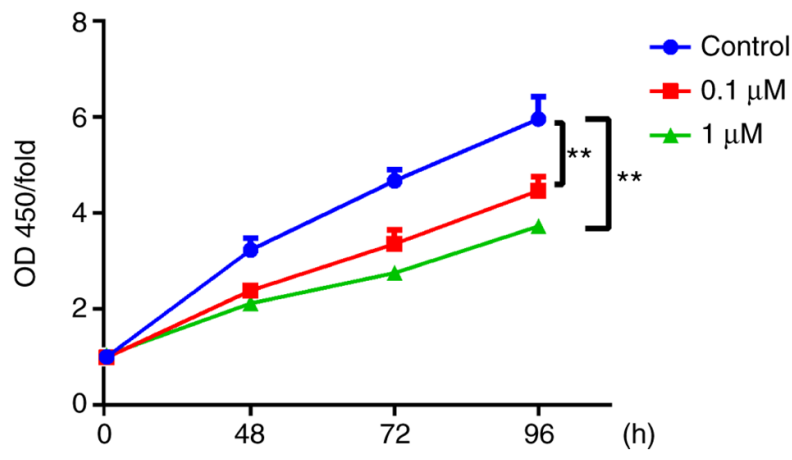

Figure 1. Nicotine suppresses the proliferation of $16 \mathrm{HBE}$ cells. 16HBE cells were seeded in 96-well flat-bottom plates at $2 \times 10^{3}$ cells/well and treated with 0.1 or $1 \mu \mathrm{M}$ nicotine for $0,48,72$ and $96 \mathrm{~h}$. Cell proliferation of nicotine-treated $16 \mathrm{HBE}$ cells was examined by Cell Counting Kit- 8 assay. Data are presented as the mean $\pm \mathrm{SD}(\mathrm{n}=3) .{ }^{* *} \mathrm{P}<0.01$ vs. 0 h. OD, optical density.

experiments. The results revealed that 0.1 and $1 \mu \mathrm{M}$ nicotine treatment significantly induced the mRNA expression levels of pro-caspase-1, IL-1 $\beta$ and IL-18 compared with the control group (Fig. 4A). Furthermore, nicotine promoted the protein expression level of caspase-1, IL-1 $\beta$ and IL-18 in 16HBE cells; however, it had no obvious effect on pro-caspase-1 (Fig. 4B). In addition, $16 \mathrm{HBE}$ cells exhibited significant increases in the protein expression levels of NLRP3 and ASC after nicotine administration compared with the control group, as determined by western blotting (Fig. 5A). The NLRP3, ASC and cleaved form of GSDMD was also significantly increased by nicotine in 16HBE cells (Fig. 5A), which is indicative of pyroptosis (34). Furthermore, the increased expression of caspase-1 was also observed in nicotine-treated $16 \mathrm{HBE}$ cells by immunofluorescence analysis (Fig. 5B). Taken together, these results suggested that pyroptosis was induced in $16 \mathrm{HBE}$ cells upon nicotine administration.

\section{Discussion}

COPD is a multifactorial disease associated with numerous mechanisms $(35,36)$. The pathogenesis of COPD involves several pathophysiological processes, such as inflammatory response, oxidative stress, apoptosis, protease/anti-proteinase imbalance, production of autoantibodies, changes in cell proliferation and aging (37). The inflammatory response and cell death are two of the most important pathogenic factors associated with COPD (38). As a novel form of programmed cell death, pyroptosis is different from apoptosis, which is classically considered a non-inflammatory form of apoptosis $(17,39)$. Molecularly, apoptosis is executed by activation of the executioner caspases, caspase-3 and caspase-7, downstream of the initiator caspases, caspase- 8 , caspase- 9 and caspase-10 (40). However, whether pyroptosis is associated with COPD pathogenesis remains to be determined.

Cigarette smoke can cause inflammation, which is an important injury factor in lung diseases such as COPD (41). The damage to the lungs caused by cigarette smoke is most directly reflected in the injury of bronchial epithelial cells and alveolar epithelial cells (42). Bronchial epithelial cells are one of the key cell types that mediate inflammation and the $16 \mathrm{HBE}$ cell line is a common cell line used to study COPD 

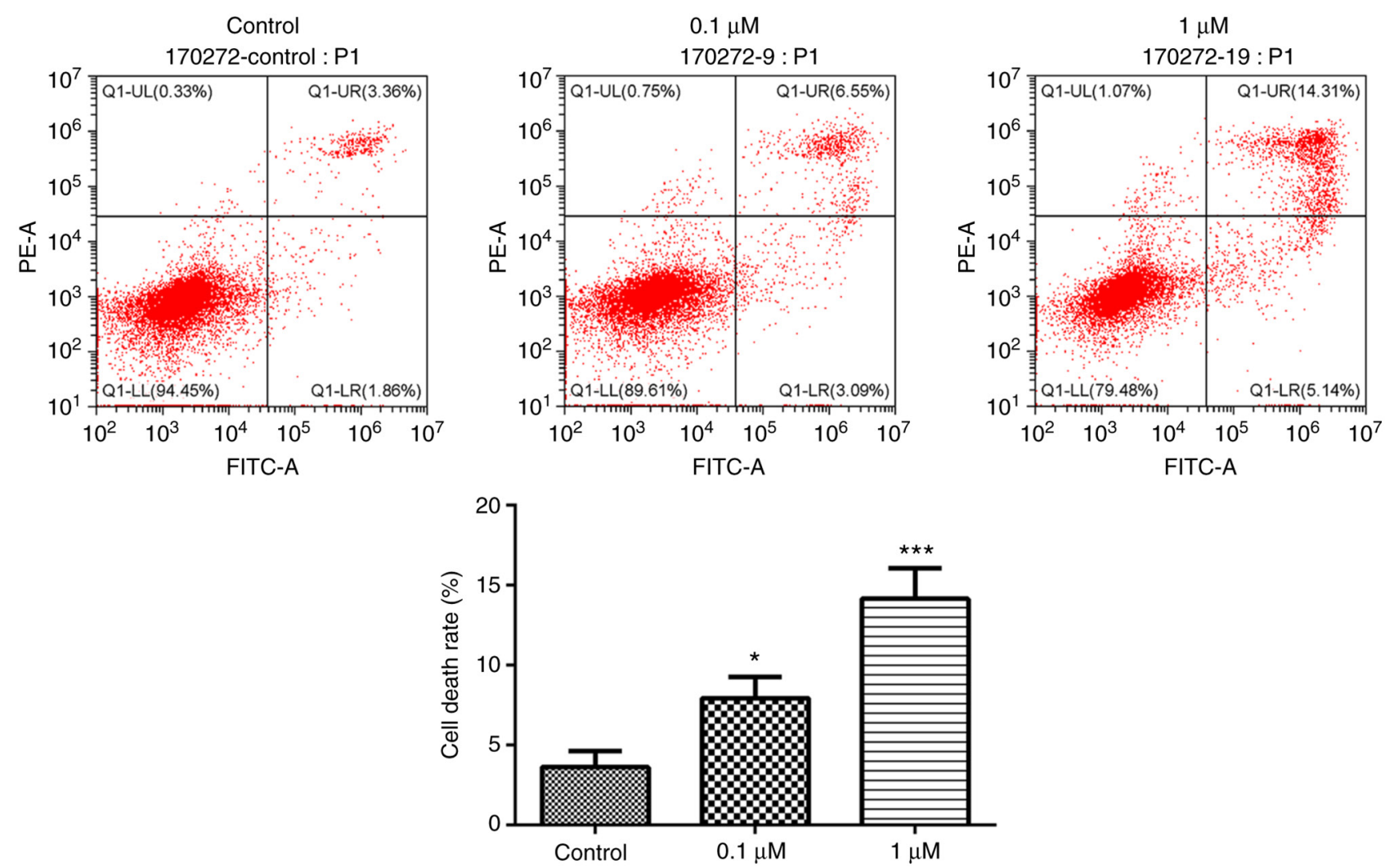

Figure 2. Nicotine induces 16HBE cell death. 16HBE cells were treated with 0.1 or $1 \mu \mathrm{M}$ nicotine for $48 \mathrm{~h}$. Nicotine-treated $16 \mathrm{HBE}$ cell death was evaluated by flow cytometry measuring Annexin V and PI. The number in each quadrant represents the percentage of cells in that compartment. Data are presented as the mean $\pm \mathrm{SD}(\mathrm{n}=3) .{ }^{*} \mathrm{P}<0.05,{ }^{* * * *} \mathrm{P}<0.001$ vs. Control.

Tunel

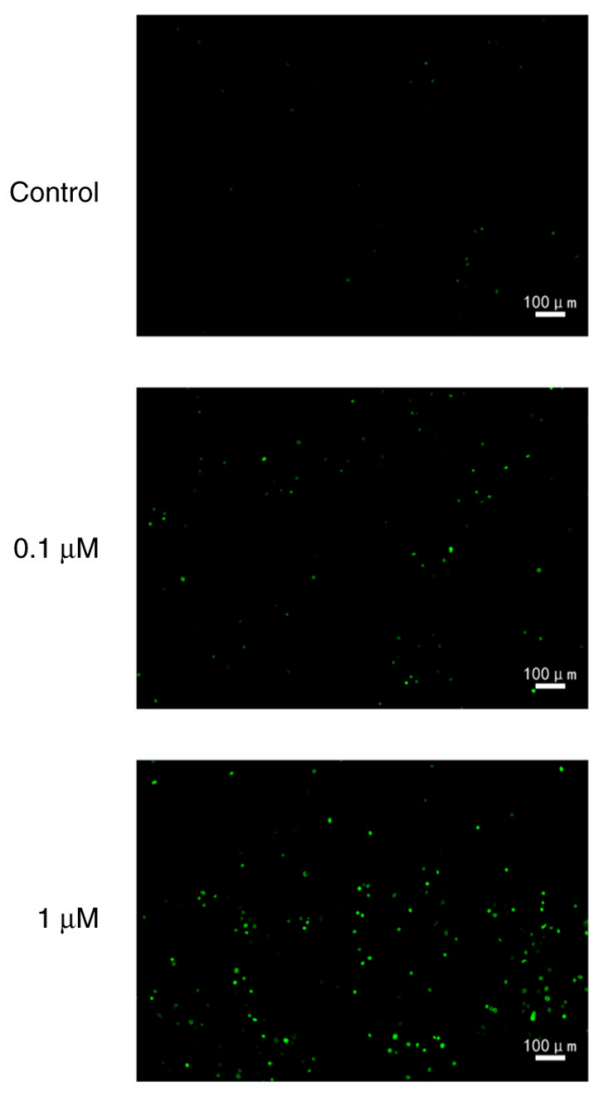

DAPI
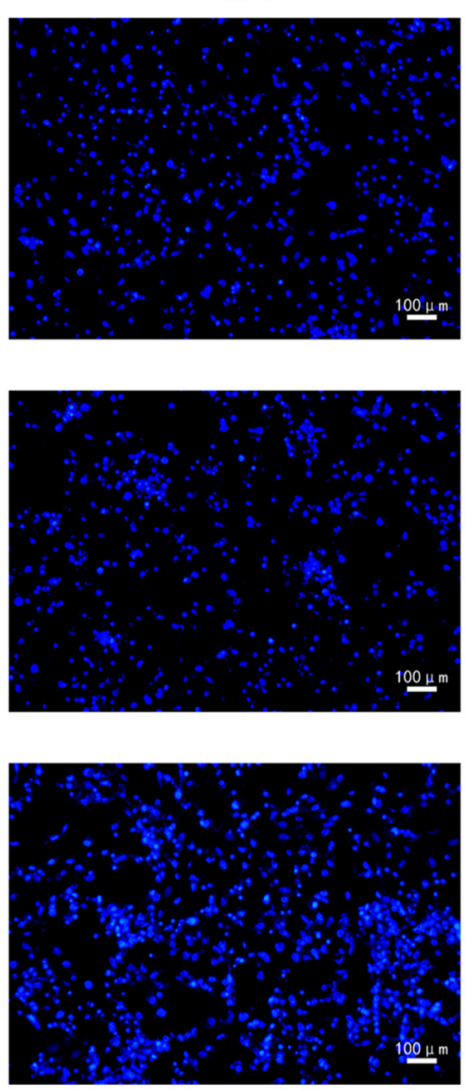

Merged
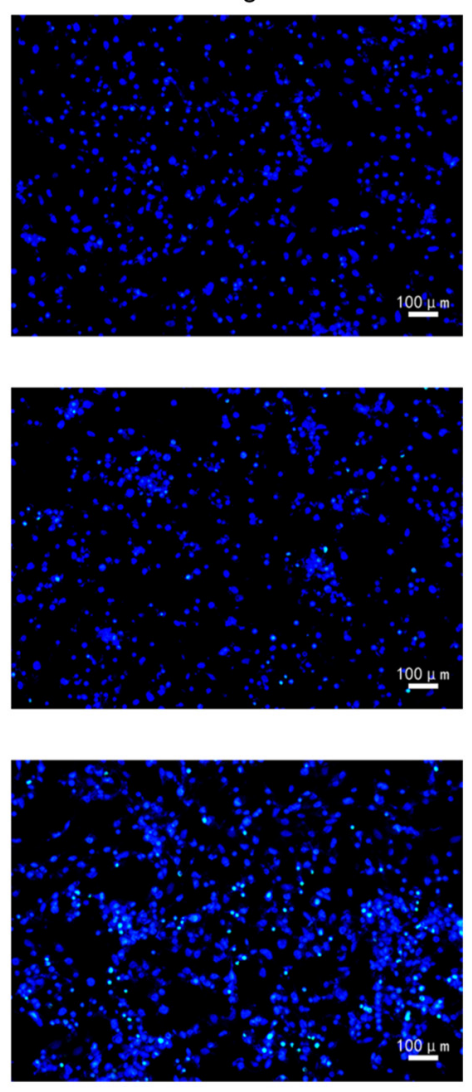

Figure 3. Nicotine induces $16 \mathrm{HBE}$ cell death. 16HBE cells were treated with 0.1 or $1 \mu \mathrm{M}$ nicotine for $48 \mathrm{~h}$. Nicotine-treated $16 \mathrm{HBE}$ cell death was examined by TUNEL staining $(\mathrm{n}=3)$. 


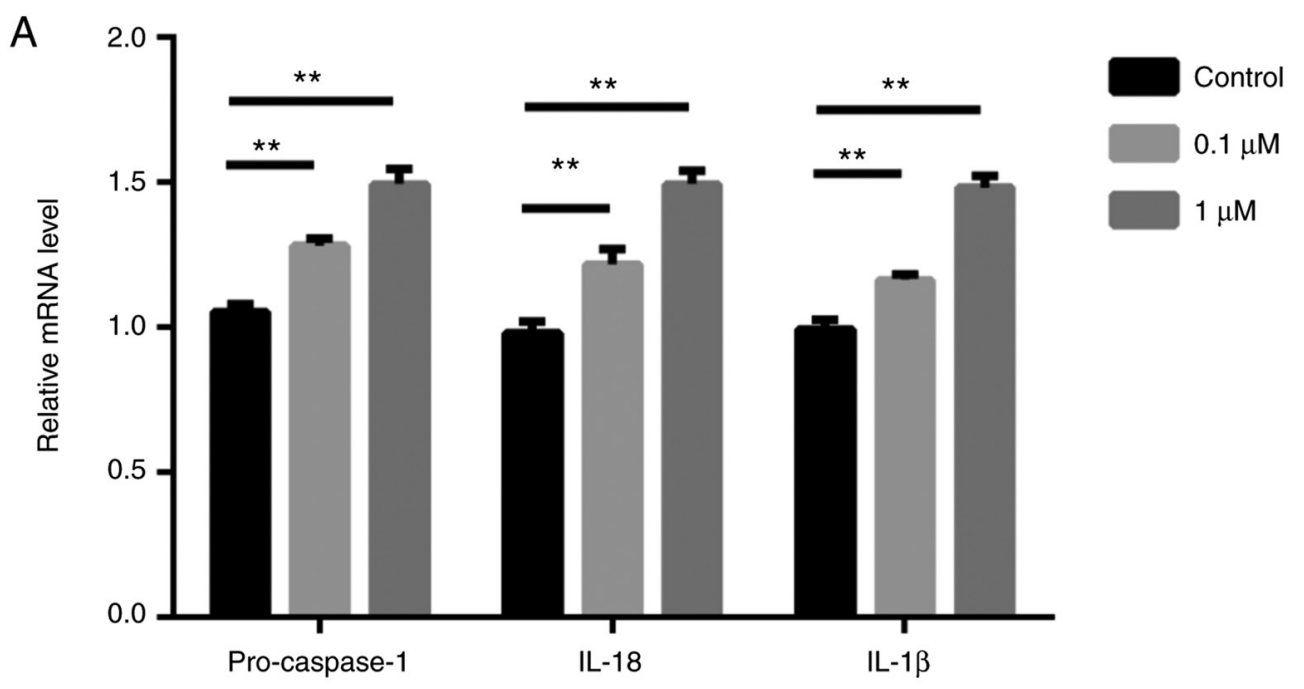

B
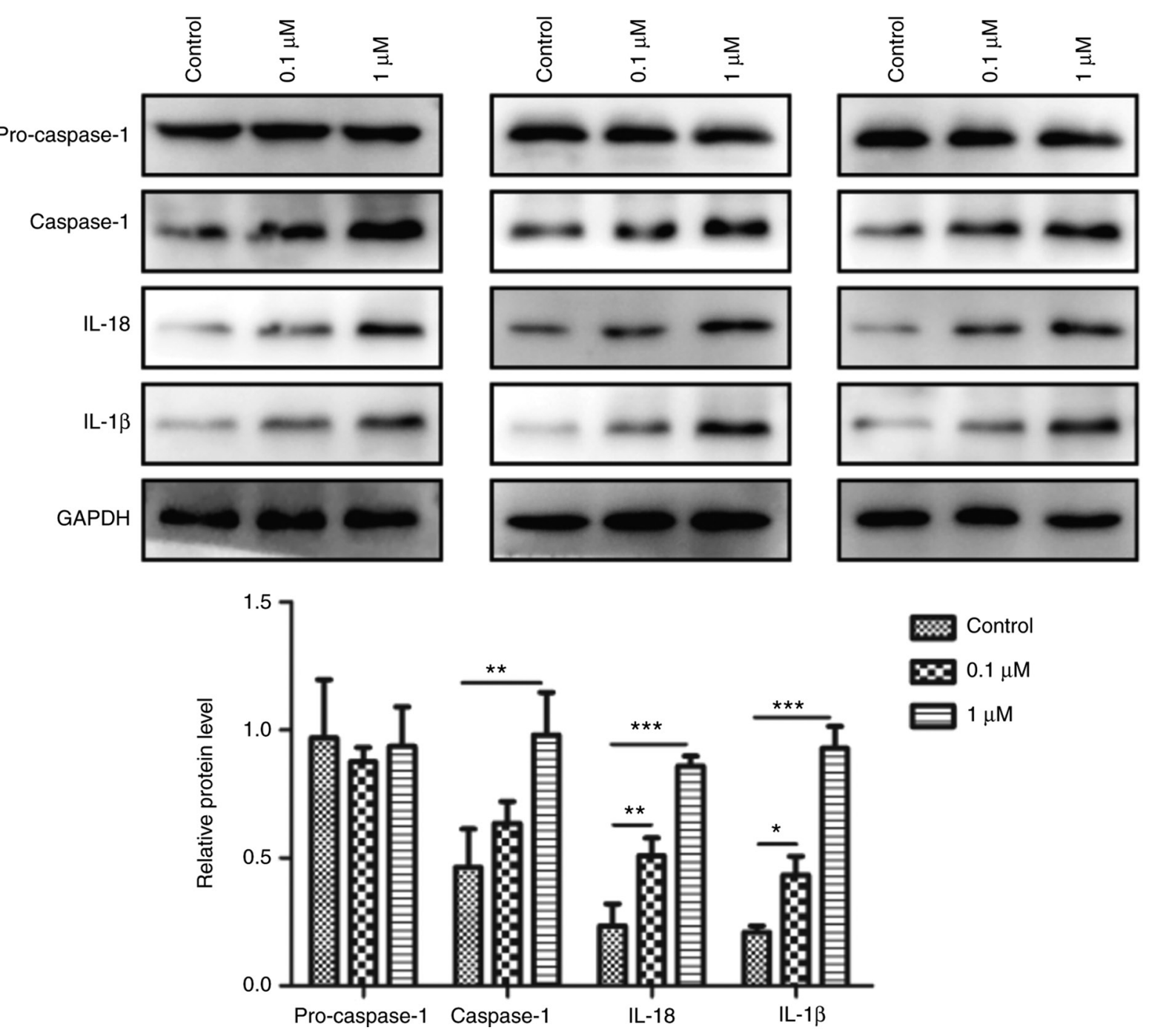

Figure 4. Epithelial cells display characteristic features of pyroptosis after nicotine exposure. 16HBE cells were treated with 0.1 or $1 \mu \mathrm{M}$ nicotine for $48 \mathrm{~h}$. (A) mRNA expression levels of caspase-1, IL-1 $\beta$ and IL-18 in nicotine-treated 16HBE cells were measured by reverse transcription-quantitative PCR. (B) Protein expression levels of pro-caspase-1, caspase-1, IL-1 $\beta$ and IL-18 in nicotine-treated 16HBE cells were measured by western blotting. GAPDH was used as a loading control. Data are presented as the mean $\pm \mathrm{SD}(\mathrm{n}=3) .{ }^{*} \mathrm{P}<0.05,{ }^{* *} \mathrm{P}<0.01,{ }^{* * *} \mathrm{P}<0.001$ vs. Control.

pathogenesis in vitro. When exposed to harmful substances, such as cigarette smoke, airway epithelial cells are induced to produce various inflammatory cytokines (e.g., IL-18) leading to the recruitment of inflammatory cells (e.g., neutrophils) (43). In vitro and in vivo studies have demonstrated that smoking causes inflammation and cell death in lung tissue and 


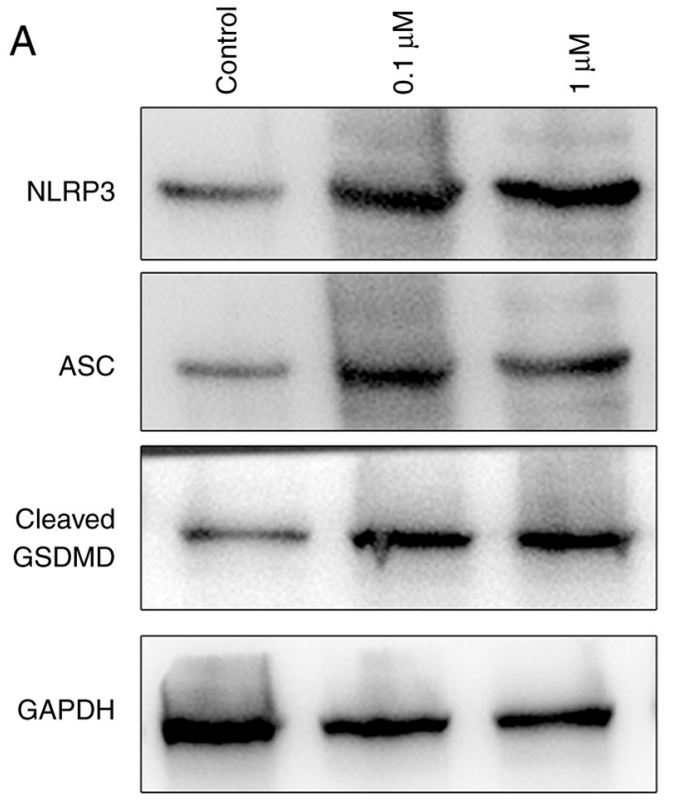

B
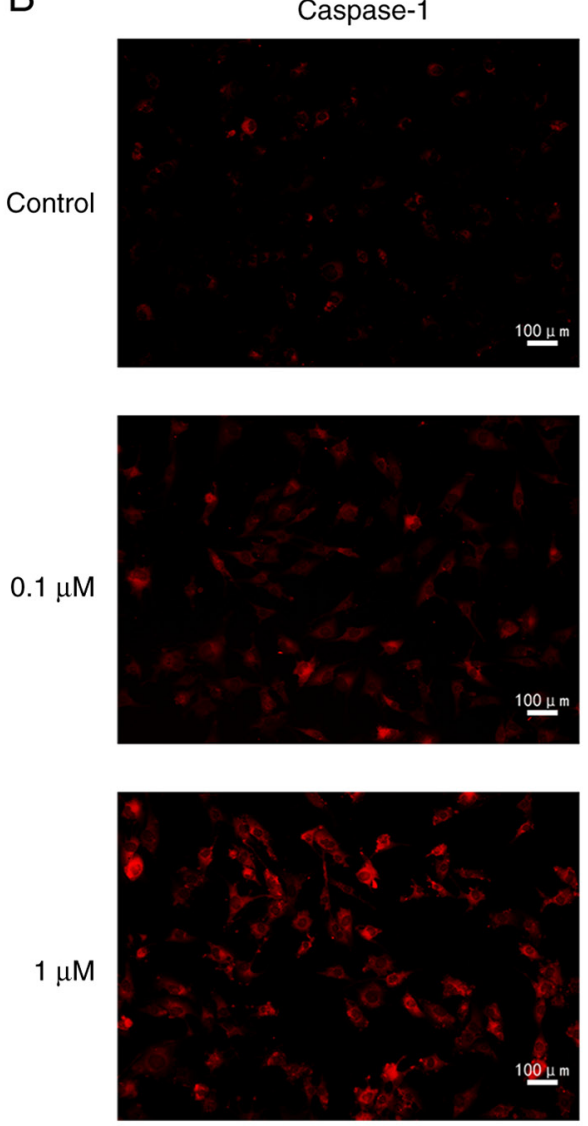

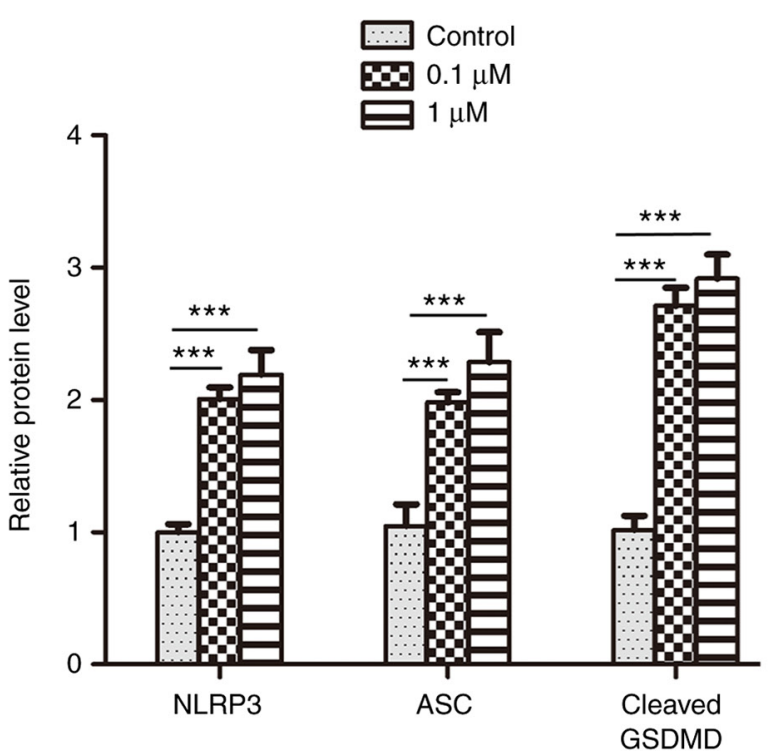

DAPI
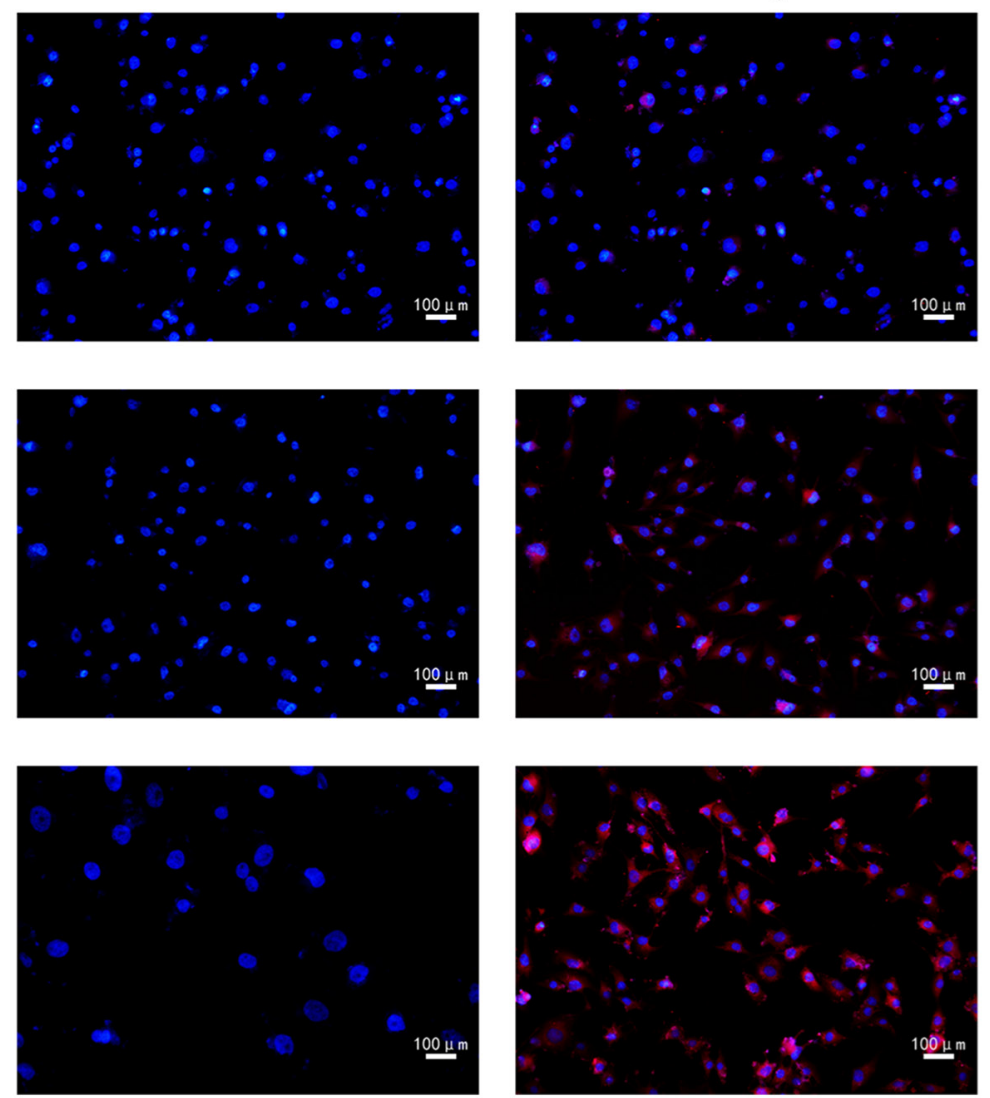

Figure 5. Nicotine increases the expression levels of NLRP3, ASC, GSDMD and caspase-1 in 16HBE cells. 16HBE cells were treated with 0.1 or $1 \mu \mathrm{M}$ nicotine for $48 \mathrm{~h}$. (A) Protein expression levels of NLRP3, ASC and GSDMD were examined by western blotting. Data are presented as the mean \pm SD (n=3). ${ }^{* * *} \mathrm{P}<0.001$ vs. Control. (B) Caspase-1 expression was detected by immunofluorescence analysis $(n=3)$. ASC, apoptosis-associated speck-like protein; NLRP3, NOD-like receptor protein 3; GSDMD, gasdermin D.

airway cells $(38,41)$. The present study revealed that treatment with 0.1 and $1 \mu \mathrm{M}$ nicotine suppressed the proliferation and promoted the death of $16 \mathrm{HBE}$ cells, as determined by CCK- 8 assay, flow cytometry and immunofluorescence analysis. Furthermore, 0.1 and $1 \mu \mathrm{M}$ nicotine treatment significantly enhanced the expression levels of caspase-1, IL-1 $\beta$, IL-18, NLRP3, ASC and GSDMD in 16HBE cells. During pyroptosis, the activated NLRP3 inflammasome can induce the cleavage of pro-caspase-1 into mature caspase-1 (44). In the present study, nicotine treatment significantly increased the 
mRNA expression levels of pro-caspase-1 but showed no effect on its protein expression levels. By contrast, nicotine exposure significantly increased the protein expression levels of caspase-1. Thus, it was hypothesized that nicotine promoted the expression of pro-caspase 1, and the increased levels of pro-caspase 1 were then cleaved into caspase-1. These results indicated that nicotine exposure may induce pyroptosis in $16 \mathrm{HBE}$ cells, suggesting that pyroptosis could be involved in the progression of COPD. This discovery sheds new light on the mechanism underlying the pathogenesis of COPD.

Bronchial epithelial cells serve an integral role in the airway defense mechanism via the mucociliary system and mechanical barriers, which serve significant roles in the progression of various lung diseases in addition to COPD, such as asthma, lung cancer, pneumonia and pulmonary fibrosis (45). Previous studies have revealed that smoking is significantly prevalent in patients with multiple lung diseases (46-48). However, to the best of our knowledge, whether nicotine exposure induces pyroptosis in these diseases remains to be elucidated. A key mediator of pyroptosis, GSDMB, has already been highly linked to asthma and non-small cell lung carcinoma (49-51). Thus, it was hypothesized that nicotine exposure may induce pyroptosis in bronchial epithelial cells in these diseases; this hypothesis requires further study.

Finally, the present study had some limitations. The in vitro experiments were only performed in $16 \mathrm{HBE}$ cells; therefore, further experiments should be performed in more cell lines to confirm the findings presented in the current study. Due to limited experimental conditions, nicotine exposure-induced pyroptosis has not been confirmed in in vivo experiments. Thus, further experimental research is needed to confirm the results in an animal model of COPD. Furthermore, it is still not clear whether nicotine exposure will induce pyroptosis in patients with COPD; this will be one of our future research directions.

In conclusion, the results of the present study suggested that nicotine exposure suppressed the proliferation and promoted the death of $16 \mathrm{HBE}$ cells, which may be associated with the increased expression levels of caspase-1, IL-1 $\beta$, IL-18, NLRP3, ASC and GSDMD. These findings indicated that nicotine treatment induced pyroptosis in $16 \mathrm{HBE}$ cells, which may be associated with the progression of COPD.

\section{Acknowledgments}

Not applicable.

\section{Funding}

This work was supported by the National Natural Science Foundation of China (grant nos. 81660013 and No.81860015).

\section{Availability of data and materials}

The datasets used and/or analyzed during the current study are available from the corresponding author on reasonable request.

\section{Authors' contributions}

YC and YD were responsible for the conception of the present study. RM, YC and YD confirm the authenticity of all the raw data. RM and JZ conducted the experiments, analyzed and interpreted the data. JZ was responsible for statistical analysis. All authors read and approved the final manuscript.

\section{Ethics approval and consent to participate}

Not applicable.

\section{Patient consent for publication}

Not applicable.

\section{Competing interests}

The authors declare that they have no competing interests.

\section{References}

1. Mouronte-Roibas C, Leiro-Fernandez V, Fernandez-Villar A, Botana-Rial M, Ramos-Hernandez C and Ruano-Ravina A: COPD, emphysema and the onset of lung cancer. A systematic review. Cancer Lett 382: 240-244, 2016.

2. Lopez-Campos JL, Tan W and Soriano JB: Global burden of COPD. Respirology 21: 14-23, 2016.

3. Gibson GJ, Loddenkemper R, Lundback B and Sibille Y: Respiratory health and disease in Europe: The new European Lung White Book. Eur Respir J 42: 559-563, 2013.

4. Mirza S, Clay RD, Koslow MA and Scanlon PD: COPD Guidelines: A review of the 2018 GOLD Report. Mayo Clin Proc 93: 1488-1502, 2018.

5. Singh D, Agusti A, Anzueto A, Barnes PJ, Bourbeau J, Celli BR, Criner GJ, Frith P, Halpin DMG, Han M, et al: Global strategy for the diagnosis, management, and prevention of chronic obstructive lung disease: The GOLD science committee report 2019. Eur Respir J 53: 1900164, 2019.

6. Sampaio MS, Vieira WA, Bernardino IM, Herval AM, Flores-Mir C and Paranhos LR: Chronic obstructive pulmonary disease as a risk factor for suicide: A systematic review and meta-analysis. Respir Med 151: 11-18, 2019.

7. Kim EJ, Yoon SJ, Kim YE, Go DS and Jung Y: Effects of aging and smoking duration on cigarette Smoke-Induced COPD severity. J Korean Med Sci 34 (Suppl 1): e90, 2018.

8. Hecht SS: Research opportunities related to establishing standards for tobacco products under the Family Smoking Prevention and Tobacco Control Act. Nicotine Tob Res 14: 18-28, 2012.

9. Gellner CA, Belluzzi JD and Leslie FM: Self-administration of nicotine and cigarette smoke extract in adolescent and adult rats. Neuropharmacology 109: 247-253, 2016.

10. Hou W, Hu S, Li C, Ma H, Wang Q, Meng G, Guo T and Zhang J: Cigarette smoke induced lung barrier dysfunction, EMT, and tissue remodeling: A possible link between COPD and lung cancer. Biomed Res Int 2019: 2025636, 2019.

11. Garcia-Arcos I, Geraghty P, Baumlin N, Campos M, Dabo AJ, Jundi B, Cummins N, Eden E, Grosche A, Salathe M and Foronjy R: Chronic electronic cigarette exposure in mice induces features of COPD in a nicotine-dependent manner. Thorax 71 : 1119-1129, 2016.

12. Tonnesen P: Smoking cessation and COPD. Eur Respir Rev 22: 37-43, 2013.

13. Liu CH, Chen Z, Chen K, Liao FT, Chung CE, Liu X, Lin YC, Keohavong P, Leikauf GD and Di YP: Lipopolysaccharide-mediated chronic inflammation promotes tobacco carcinogen-induced lung cancer and determines the efficacy of immunotherapy. Cancer Res 81: 144-157, 2021.

14. Conlon TM, John-Schuster G, Heide D, Pfister D, Lehmann M, Hu Y, Ertuz Z, Lopez MA, Ansari M, Strunz M, et al: Inhibition of LTbetaR signalling activates WNT-induced regeneration in lung. Nature 588: 151-156, 2020.

15. Li T, Fanning KV, Nyunoya T, Chen Y and Zou C: Cigarette smoke extract induces airway epithelial cell death via repressing PRMT6/AKT signaling. Aging (Albany NY) 12: 24301-24317, 2020.

16. Fang Y, Tian S, Pan Y, Li W, Wang Q, Tang Y, Yu T, Wu X, Shi Y $\mathrm{Ma} P$ and Shu Y: Pyroptosis: A new frontier in cancer. Biomed Pharmacother 121: 109595, 2020. 
17. Riegman M, Sagie L, Galed C, Levin T, Steinberg N, Dixon SJ, Wiesner U, Bradbury MS, Niethammer P, Zaritsky A and Overholtzer M: Ferroptosis occurs through an osmotic mechanism and propagates independently of cell rupture. Nat Cell Biol 22: 1042-1048, 2020.

18. Li N, Zhou H, Wu H, Wu Q, Duan M, Deng W and Tang Q: STING-IRF3 contributes to lipopolysaccharide-induced cardiac dysfunction, inflammation, apoptosis and pyroptosis by activating NLRP3. Redox Biol 24: 101215, 2019.

19. Jiang S, Zhang H, Li X, Yi B, Huang L, Hu Z, Li A, Du J, Li Y and Zhang W: Vitamin D/VDR attenuate cisplatin-induced AKI by down-regulating NLRP3/Caspase-1/GSDMD pyroptosis pathway. J Steroid Biochem Mol Biol 206: 105789, 2021.

20. Anderson FL, von Herrmann KM, Andrew AS, Kuras YI, Young AL, Scherzer CR, Hickey WF, Lee SL and Havrda MC: Plasma-borne indicators of inflammasome activity in Parkinson's disease patients. NPJ Parkinsons Dis 7: 2, 2021.

21. de Zoete MR, Palm NW, Zhu S and Flavell RA: Inflammasomes. Cold Spring Harb Perspect Biol 6: a016287, 2014.

22. Murray LA, Dunmore R, Camelo A, Da Silva CA, Gustavsson MJ, Habiel DM, Hackett TL, Hogaboam CM, Sleeman MA and Knight DA: Acute cigarette smoke exposure activates apoptotic and inflammatory programs but a second stimulus is required to induce epithelial to mesenchymal transition in COPD epithelium. Respir Res 18: 82, 2017.

23. Kang MJ, Homer RJ, Gallo A, Lee CG, Crothers KA, Cho SJ, Rochester C, Cain H, Chupp G, Yoon HJ and Elias JA: IL-18 is induced and IL-18 receptor alpha plays a critical role in the pathogenesis of cigarette smoke-induced pulmonary emphysema and inflammation. J Immunol 178: 1948-1959, 2007.

24. Franklin BS, Bossaller L, De Nardo D, Ratter JM, Stutz A, Engels G, Brenker C, Nordhoff M, Mirandola SR, Al-Amoudi A, et al: The adaptor ASC has extracellular and 'prionoid' activities that propagate inflammation. Nat Immunol 15: 727-737, 2014.

25. Guan R, Wang J, Cai Z, Li Z, Wang L, Li Y, Xu J, Li D, Yao H, Liu W, et al: Hydrogen sulfide attenuates cigarette smoke-induced airway remodeling by upregulating SIRT1 signaling pathway. Redox Biol 28: 101356, 2020

26. Plataki M, Tzortzaki E, Rytila P, Demosthenes $M$ Koutsopoulos A and Siafakas NM: Apoptotic mechanisms in the pathogenesis of COPD. Int J Chron Obstruct Pulmon Dis 1: 161-171, 2006

27. Park JW, Ryter SW and Choi AM: Functional significance of apoptosis in chronic obstructive pulmonary disease. COPD 4 347-353, 2007.

28. Kim SY, Kim HJ, Park MK, Huh JW, Park HY, Ha SY, Shin JH and Lee YS: Mitochondrial E3 Ubiquitin Protein Ligase 1 Mediates Cigarette Smoke-Induced endothelial cell death and dysfunction. Am J Respir Cell Mol Biol 54 284-296, 2016.

29. Sun Y, An N, Li J, Xia J, Tian Y, Zhao P, Liu X, Huang H, Gao J and Zhang X: MiRNA-206 regulates human pulmonary microvascular endothelial cell apoptosis via targeting in chronic obstructive pulmonary disease. J Cell Biochem 120: 6223-6236, 2019.

30. Waltl EE, Selb R, Eckl-Dorna J, Mueller CA, Cabauatan CR, Eiwegger T, Resch-Marat Y, Niespodziana K, Vrtala S, Valenta R and Niederberger V: Betamethasone prevents human rhinovirusand cigarette smoke-induced loss of respiratory epithelial barrier function. Sci Rep 8: 9688, 2018.

31. Takahashi T, Yoshida T, Harada K, Miyagi T, Hashimoto K, Hide I, Tanaka S, Irifune M and Sakai N: Component of nicotine-induced intracellular calcium elevation mediated through $\alpha 3$ - and $\alpha 5$-containing nicotinic acetylcholine receptors are regulated by cyclic AMP in SH-SY 5Y cells. PLoS One 15: e0242349, 2020

32. Livak KJ and Schmittgen TD: Analysis of relative gene expression data using real-time quantitative PCR and the 2(-Delta Delta C(T)) Method. Methods 25: 402-408, 2001.

33. Xu R, Li Q, Zhou J, Zhou XD, Perelman JM and Kolosov VP: The degradation of airway tight junction protein under acidic conditions is probably mediated by transient receptor potential vanilloid 1 receptor. Biosci Rep 33: e00078, 2013.
34. Hu JJ, Liu X, Xia S, Zhang Z, Zhang Y, Zhao J, Ruan J, Luo X, Lou X, Bai Y, et al: FDA-approved disulfiram inhibits pyroptosis by blocking gasdermin D pore formation. Nat Immunol 21: 736-745, 2020 .

35. Barnes PJ: Inflammatory mechanisms in patients with chronic obstructive pulmonary disease. J Allergy Clin Immunol 138: $16-27,2016$

36. Polverino F, Celli BR and Owen CA: COPD as an endothelial disorder: Endothelial injury linking lesions in the lungs and other organs? (2017 Grover Conference Series). Pulm Circ 8: $2045894018758528,2018$.

37. Yao H and Rahman I: Current concepts on oxidative/carbonyl stress, inflammation and epigenetics in pathogenesis of chronic obstructive pulmonary disease. Toxicol Appl Pharmacol 254: 72-85, 2011

38. Hikichi M, Mizumura K, Maruoka S and Gon Y: Pathogenesis of chronic obstructive pulmonary disease (COPD) induced by cigarette smoke. J Thorac Dis 11 (Suppl 17): S2129-S2140, 2019.

39. Hsu SK, Li CY, Lin IL, Syue WJ, Chen YF, Cheng KC, Teng YN, Lin $\mathrm{YH}$, Yen $\mathrm{CH}$ and Chiu CC: Inflammation-related pyroptosis, a novel programmed cell death pathway, and its crosstalk with immune therapy in cancer treatment. Theranostics 11: 8813-8835, 2021.

40. Wang Y and Kanneganti TD: From pyroptosis, apoptosis and necroptosis to PANoptosis: A mechanistic compendium of programmed cell death pathways. Comput Struct Biotechnol J 19: 4641-4657, 2021.

41. John G, Kohse K, Orasche J, Reda A, Schnelle-Kreis J, Zimmermann R, Schmid O, Eickelberg O and Yildirim AO: The composition of cigarette smoke determines inflammatory cell recruitment to the lung in COPD mouse models. Clin Sci (Lond) 126: 207-221, 2014.

42. Sarker RSJ, Conlon TM, Morrone C, Srivastava B, Konyalilar N, Verleden SE, Bayram H, Fehrenbach $\mathrm{H}$ and Yildirim AO: CARM1 regulates senescence during airway epithelial cell injury in COPD pathogenesis. Am J Physiol Lung Cell Mol Physiol 317: L602-L614, 2019.

43. Zou Y, Chen X, He B, Xiao J, Yu Q, Xie B, Yang S, Dai L, Dai Z and Chen Q: Neutrophil extracellular traps induced by cigarette smoke contribute to airway inflammation in mice. Exp Cell Res 389: 111888, 2020.

44. Li H, Lu R, Pang Y, Li J, Cao Y, Fu H, Fang G, Chen Q, Liu B, Wu J, et al: Zhen-Wu-Tang Protects IgA nephropathy in rats by regulating exosomes to inhibit NF- $\kappa \mathrm{B} / \mathrm{NLRP} 3$ Pathway. Front Pharmacol 11: 1080, 2020.

45. Takizawa H: Bronchial epithelial cells in allergic reactions. Curr Drug Targets Inflamm Allergy 4: 305-311, 2005.

46. Kim SY, Sim S and Choi HG: Active, passive, and electronic cigarette smoking is associated with asthma in adolescents. Sci Rep 7: 17789, 2017.

47. Kalemkerian GP and Schneider BJ: Advances in small cell lung cancer. Hematol Oncol Clin North Am 31: 143-156, 2017.

48. Margaritopoulos GA, Harari S, Caminati A and Antoniou KM: Smoking-related idiopathic interstitial pneumonia: A review. Respirology 21: 57-64, 2016.

49. Das S, Miller M and Broide DH: Chromosome 17q21 Genes ORMDL 3 and GSDMB in asthma and immune diseases. Adv Immunol 135: 1-52, 2017

50. Peng Z, Wang P, Song W, Yao Q, Li Y, Liu L, Li Y and Zhou S: GSDME enhances Cisplatin sensitivity to regress non-small cell lung carcinoma by mediating pyroptosis to trigger antitumor immunocyte infiltration. Signal Transduct Target Ther 5: 159, 2020

51. Soy M, Keser G, Atagunduz P, Tabak F, Atagunduz I and Kayhan S: Cytokine storm in COVID-19: Pathogenesis and overview of anti-inflammatory agents used in treatment. Clin Rheumatol 39: 2085-2094, 2020 .

This work is licensed under a Creative Commons Attribution-NonCommercial-NoDerivatives 4.0 International (CC BY-NC-ND 4.0) License. 